\title{
An unusual case of primary intrascrotal lipoma
}

\author{
Andrea Fabiani ${ }^{1}$, Emanuele Principi ${ }^{2}$, Alessandra Filosa ${ }^{3}$, Tiziana Pieramici ${ }^{3}$, Fabrizio Fioretti ${ }^{1}$, \\ Valentina Maurelli ${ }^{1}$, Lucilla Servi ${ }^{1}$, Gabriele Mammana ${ }^{1}$ \\ ${ }^{1}$ Urology Unit, Surgery Department, Macerata Civic Hospital, Area Vasta 3 ASUR Marche, Italy; \\ ${ }^{2}$ Urologic Clinic, Polytechnic University of Marche Region, Ancona, Italy; \\ ${ }^{3}$ Pathologic Unit ASUR Marche Area Vasta 3, Macerata Civic Hospital, Italy.
}

\begin{abstract}
Summary In daily clinical practice, intrascrotal lesion are commonly detected, both by clinical examination either by ultrasound scan. While 95\% of testicular lesions are malignant, most paratesticular lesions are benign. Among these, intrascrotal lipomas must be take into account in differential diagnosis. When they originate from scrotal wall, they named "primary scrotal lipoma". We describe a case of a primary intrascrotal lipoma diagnosed after surgical excision in a young man presented at our Urological Department complaining a painful left scrotal mass.
\end{abstract}

KEY WORDS: Scrotal lipoma; Paratesticular tumor; Scrotal ultrasound.

Submitted 15 November 2016; Accepted 15 December 2016

\section{INTRODUCTION}

Intrascrotal lipomas are lesions rarely observed in common clinical practice. They are benign mesenchymal tumours that can arise from the paratesticular structures as the spermatic cord, epididymis, tunica vaginalis or from the subcutaneous adipose cell of the scrotum (1). In most cases it is not easy to identify the precise source site of these tumors. When lipomas originate from scrotal wall they are named "primary scrotal lipomas" (2) such in the case reported herein.

\section{Case presentation}

A 22-years-old patient presented to our Hospital with a painful nodule of a left scrotal region, that was first noticed about 3 months before but gradually and slowly became symptomatic. No others symptoms were reported in anamnesis. At palpation, the nodule showed an elastic non tender consistency and it resulted regularly shaped on the left side of the scrotum apart of the lower ipsilateral testicular pole. It was easily distinguishable from testicle and epidydimus that appeared normal for shape and size and not painful. The contralateral testicle and epidydimus were normal. The scrotal ultrasound, performed with a 7,5 Mhz linear probe, showed a slightly hyperechoic homogeneous nodule, that does not show any infiltrative character and was $3 \times 2 \mathrm{~cm}$ in size (Figure 1). No echocolor signal was present. Therefore, due to the difficult interpretation and to the symptoms complained, it was decided to perform a scrotal surgical exploration. After a local anesthesia with left funicular and median raphe infiltration (Lidocaine 2\% $10 \mathrm{ml}$ and Ropivacaine $7,5 \mathrm{mg} 10 \mathrm{ml}$ ), a longitudinal median scrotal incision was made. An ovoid intrascrotal mass was externalized (Figure 2).

Figure 1.

Scrotal ultrasound shows a slightly hyperechoic homogeneous nodule without color signal expression.

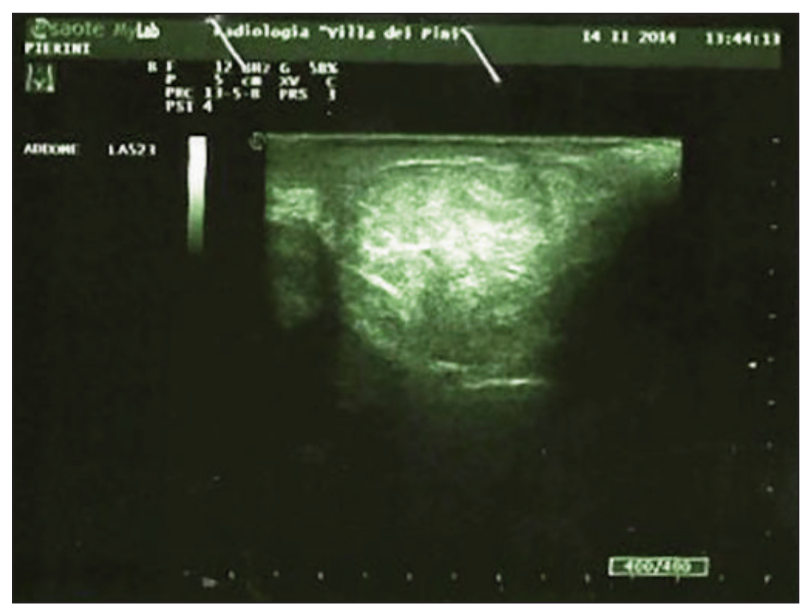

Figure 2.

Nodule appearance at surgical exploration.

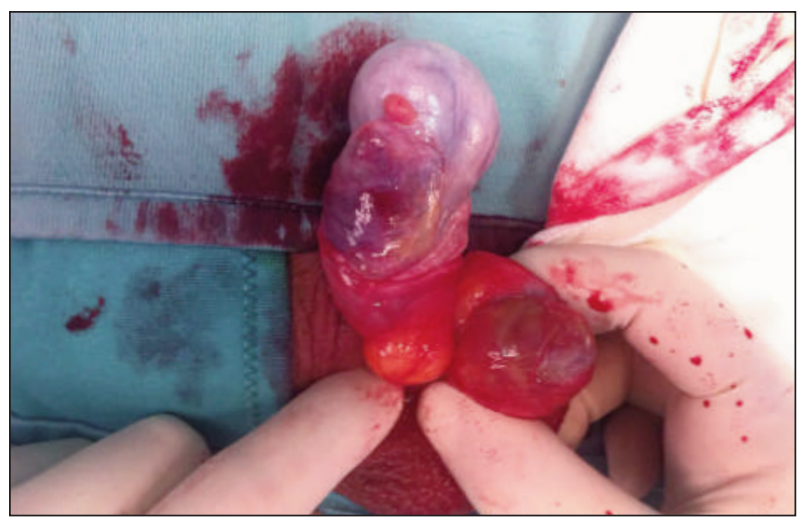




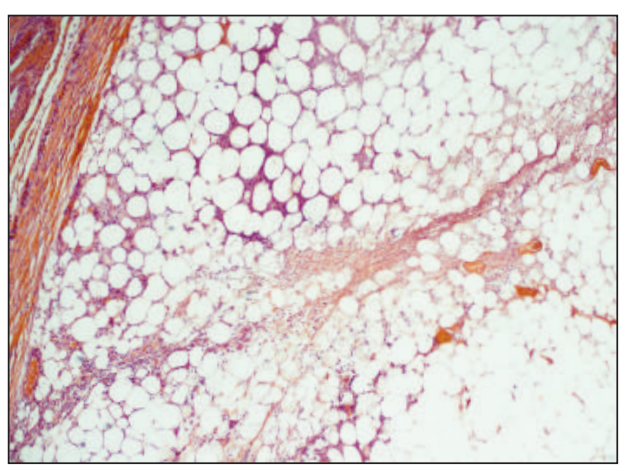

Figure 3.

Hystological features of the nodule.

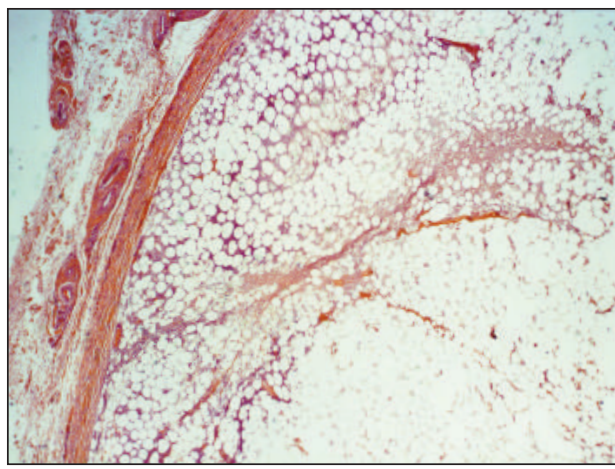

A.

B.

The yellowish mass of about $3 \mathrm{~cm}$ in major diameter, was completely excised from the scrotal wall. The left testicle and epidydimus were normal. After excision and eversion of tunica vaginalis, scrotal wall was sutured with absorbable stiches. A drainage was placed in paratesticular space to avoid haematocele. The microscopic pathologic evaluation of the surgical specimen highlighted the presence of mature adipocytes constituting the totality of the tissue examined in the absence of other types of connective tissue and an obvious abnormal vascular proliferation vascular with steatonecrosis areas and, at the periphery of the lesion, a reactive vascular proliferation like a granulation tissue (Figure 3a, b). The diagnosis of primary scrotal lipoma was made.

\section{Discussion}

In daily clinical practice, intrascrotal lesion are commonly detected, both by clinical examination either by ultrasound scan. While $95 \%$ of testicular lesions are malignant, most paratesticular lesions are benign. Among these, the intrascrotal lipomas are rare lesion. The region of origin are not always detectable and they may originate from the adipose tissue of spermatic cord, spermatic cord structures and the scrotal wall (3).

The patient age may be a guide to clinical diagnosis (1). They may also be malignant and vary in size.

Consequently symptoms are caused by growth. Ultrasound imaging play an important role in the initial evaluation of these lesions. providing information about localization, cystic or solid nature of the lesion (3).

Then, these lesions can be distinguished from most other testicular lesions, such as fibrous pseudotumor, adenomatoid tumor or cystic lesions, according to ultrasound findings, anatomic location, and negative tumor markers.
However, even using these findings it is difficult to radiologically determinate the nature of these lesions (benign or malignant). Although the majority of solid extratesticular masses are benign, it is hard to distinguish malignancy (4). In conditions like these, Magnetic Resonance Imaging may be of use. The histopathology of primary scrotal lipoma may be confused with lipomatosis, lipoblastoma and liposarcoma. Being the mass encapsulated and not infiltrated to the surrounding tissues helped us to differentiate it from lipomatosis, and the presence of mitosis and atypia to differentiate it from liposarcoma. No malignancy was present in the case reported. On the third and sixth month follow-up no local relapse was seen.

\section{Conclusion}

Scrotal lipomas are rare, benign paratesticular tumors. Surgical excision is the treatment of choice. There is no evidence that scrotal lipomas differ in terms of management and prognosis from other variants of lipoma. Although the sonographic appearance of these tumors is variable and non-specific, ultrasound is the first exam in the clinical management as for all scrotal masses and it has a key role in the initial management.

\section{AUTHORS' CONTRIBUtIONS}

All Authors participated in the design and conduct of the study. All Authors reviewed and approved the final version of the manuscript.

\section{References}

1. Algaba F, Mikuz G, Boccon-Gibod L, et al. Pseudoneoplastic lesions of the testis and paratesticular structures. Virchows Arch. 2007; 451:987-97.

2. Fujimura N, Kurokawa K. Primary lipoma of the scrotum. Eur Urol. 1979; 5:182-183.

3. Galosi AB, Scarpelli M, Mazzucchelli R, et al. Adult paratesticular mesenchymal tumors with emphasis on a case presentation and discussion of spermatic cord leiomyosarcoma. Diagnostic Pathology. 2014; 9:90.

4. Basal S, Malkoç E, Aydur E, et al. Fibrous pseudotumors of the testis: The balance between sparing the testis and preoperative diagnostic difficulty. Turkish Journal of Urology. 2014; 40:125-9.

\section{Correspondence}

Andrea Fabiani, MD (Corresponding Author) - andreadoc1@libero.it Fabrizio Fioretti, MD PhD - fa.fioretti@libero.it

Valentina Maurelli, MD - valentinamaurelli@hotmail.it

Lucilla Servi, MD - lucilla.servi@sanita.marche.it

Surgery Dpt, Section of Urology, ASUR Marche Area Vasta 3

Macerata Hospital, Macerata, Italy

Emanuele Principi, MD, Urology Resident - principie@tiscali.it Urologic Clinic, Polytechnic University of Marche Region, Ancona, Italy

Alessandra Filosa, MD, PhD - alessandrafilosa@yahoo.it

Tiziana Pieramici, MD - t.pieramici@libero.it

Section of Pathological Anatomy, Department of Clinical Pathology,

Area Vasta 3, ASUR Marche, Macerata Hospital, Macerata, Italy

Gabriele Mammana, MD - gabriele.mammana@sanita.marche.it Head Surgery Dpt, Chief of Section of Urology

ASUR Marche Area Vasta 3, Macerata Hospital, Macerata, Italy 